\title{
Smart Bin Implementation for Smart City
}

\author{
Manish S Singh ${ }^{1}$, Krishna Mohan Singh ${ }^{2}$, Ranjeet Kumar Ranjeet ${ }^{3}$, Karunesh Kumar Shukla ${ }^{4}$ \\ Department of Computer Engineering, Dr. DY Patil Institute of Technology, Pimpri, Pune 1,2,3,4 $^{2}$
}

\begin{abstract}
In our town persistently we tend to see that the garbage bins or dustbins placed at public places are overflowing. It creates unsanitary conditions for people. Conjointly it creates ugliness to it place. At a similar time unhealthy smell is additionally unfold. To avoid all such things we are attending to implement a project referred to as garbage collection bin overflow indicator mistreatment GSM and IOT technology. During this project we tend to area unit attending to place level detector within the ash-bin. Once the dirt reaches to the threshold value, a SMS will be sent to the several Municipal / Government authority person with location of that dirt bin by mistreatment GPS. Or usually we tend to see that they need a daily schedule of finding out these garbage bins or dustbins. This schedule varies as per the population of that place. But we tend to see that just in case there's some competition or some perform, a lot of garbage material is generated by people therein specific space. In such cases the garbage dustbin gets at once full so it overflows that creates several issues. Therefore in things, with facilitate of our project the govt. authority person will get SMS at once. So that they can get SMS before their periodic interval visit of finding out the dustbin.
\end{abstract}

Keywords: ARM 7, GSM, GPS, Level sensor, Garbage overflow indicator etc.

\section{INTRODUCTION}

Last few years have witnessed an amazing growth within the rate of population that silent a necessity of economical urban development plans. Currently exploitation rising technologies and very important approach, sensible cities area unit developing everywhere the planet. While not a sensible waste management system, any sensible town is incomplete. This paper represents the appliance of planned model the garbage collection system of residential or business areas. Within the planned system, the extent of waste within the garbage bin has been detected with the assistance of level sensor and it'll ceaselessly communicate to the authorized control room through GSM module. Micro-controller is employed to interface the detector system with GSM system. An interface is additionally developed to supervise the required info associated with the rubbish for numerous hand-picked locations. This method can facilitate to assure a healthy and hygienic environment.

Nowadays population is increasing quickly, which ends in lack of public awareness and folks invest less cash in program associated with the waste management. This has been making an enormous health problems everywhere the planet. Correct management of waste materials is very important to keep up healthy and hygienic environment to measure. As per the analysis of CPHEEO (Central Public Health and Environmental Engineering Organization) the total quantity of waste generated in Asian country is around one.3 pounds per person each single day. This figure is relatively less compared to four.6 pounds of waste generated per person on a daily basis within the United State (U.S.). But the U.S. population was around 307 million in Gregorian calendar month 2009, whereas India's population was one. 2 billion. These statistics shows that Asian country is generating nearly twenty seven million additional heaps of waste than the U.S. every year. Governments of Asian country are troubled for several years to search out how to manage the country's increasing quantity of garbage.

\section{LITERATUREREVIEW}

[1]A novel Approach to Garbage Management victimization internet of Things for smart Cities KasliwalManasi H, Suryawanshi Smitkumar B.2

In this system Arduino Uno board, ultrasonic device, GSM module and MATLAB primarily based user interface. The specifications of all modules square measure noncommissioned one by one very well within the following subdivision. Arduino Uno is ATmega328 microcontroller primarily based board. It operates on sixteen $\mathrm{MHz}$ clock frequency. Its operational frequency of $5 \mathrm{~V}$ and input voltage as $7-12 \mathrm{~V}$. It consists of total fourteen digital $\mathrm{I} / \mathrm{O}$ pins and analog I/O pins. ATmega328 has thirty two KB of nonvolatile storage out of that zero.5KB memory is employed by boot loader. Arduino Uno board consists of external power provide reset switch USB plug etc.

[2] Internet of Things: Challenges and state-of-theart solutions in internet-scale sensor information Management and Mobile analytics by Arkady Zaslavsky, Dimitrios Georgakopoulos.

This paper gave us the main points concerning mobile analysis and device info management which will facilitate in information segregation of varied dustbins.

[3] Top-k query based dynamic scheduling for IoTenabled small city waste collection by Theodoros Anagnostopoulos, 
Arkady Zaslavsky, Alexey Medvedev, and Sergei Khoruzhnicov. S

It gave us the thought of dynamic programming needed for the improvement of dustbin and therefore the Top-k question led us to priority primarily based improvement of dustbins

[4]City garbage collection indicator using RF (Zigbee) and GSM technology.

This paper gave the main points for the module needed for the transmission of the info to the receiver facet and conjointly the most channel follow of the project. At the start we have a tendency to used GSM technology for our project however presently set to us Wi-Fi module for the convenience of information transmission.

\section{SYSTEM ARCHITECTURE}

Internet and its applications became an integral a part of today's human lifestyle. It's become a necessary tool in each side. Because of the tremendous demand and necessity, researchers went on the far side connecting simply computers into the online. These researches led to the birth of a sensational gizmo, internet of Things (IOT).

Communication over the web has grown up from user - user interaction to device - device interactions currently. The IOT ideas were projected years back however still it's within the initial stage of economic preparation. Home automation business and transportation industries are seeing rapid growth with IOT.

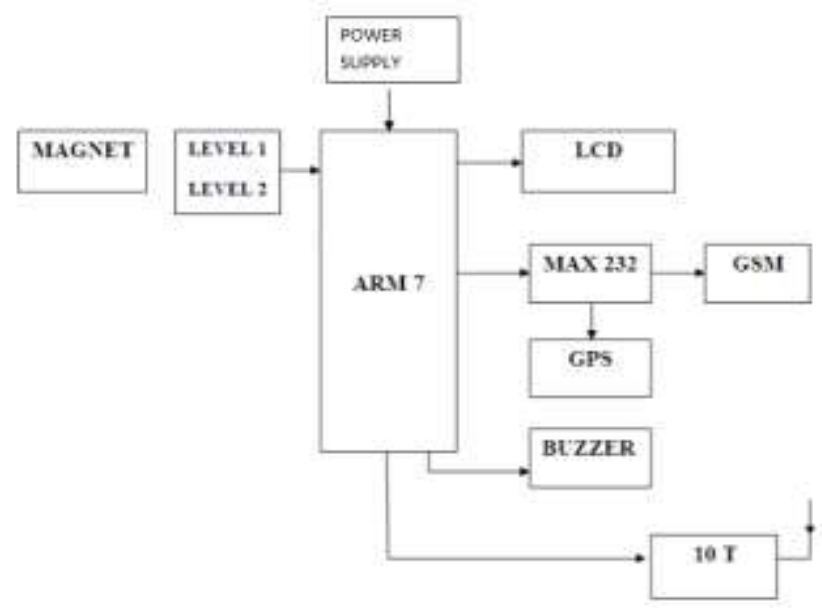

Figure: Block diagram of the System

Yet not several articles are revealed during this field of study. This paper aims in structuring a state of the art review on IOT. The technology, history and applications are mentioned shortly beside numerous statistics. Since most of the method is finished through the internet. We should have a lively high speed internet affiliation. The technology may be merely explained as an affiliation between human's computers-things. All the equipment's we tend to use in our day to day life may be controlled and monitored mistreatment the IOT. A majority of method is finished with the assistance of sensors in IOT. Sensors area unit deployed everyplace and these sensors convert raw physical information into digital signals and transmits them to its management center. By this manner we will monitor setting changes remotely from any a part of the world via net. This systems design would be supported context of operations and processes in period situations. In projected system we tend to are mistreatment level sensor to find the extent of garbage in dust beans. We tend to are using two level sensors for that purpose. Level sensor can send information to controller if dust bins are filled with garbage. Liquid crystal displaywill show the message that bins are full. Location of bins is send to licensed range using GPS and GSM. IOT can update the location on net within the kind of wave using GPS. We are using IOT for on-line updating.

\section{SYSTEM REQUIREMENT}

\section{HARDWARE}

- ARM 7 microcontroller

- Level sensor

- IOT

- GSM

- GPS

- LCD 16x2

- MAX 232 


\section{SOFTWARE}

- Keil

- Proteus

- Flash magic

\section{HARDWARE DESCRIPTION:}

\section{A. ARM 7}

The LPC2148 rely upon a 16/32 bit ARM7TDMl-S central processor with constant imitating and constituted follow bolster, beside 128/512 kilobytes of put in speedy glimmer memory. A 128-piece wide memory interface and a remarkable quickening agent design empower 32-bit code execution at the most extreme clock rate. For basic code estimate applications, the choice 16-bit Thumb Mode decreases code by quite half-hour with negligible execution penalty. With their stripped sixty four stick bundle, low power utilization, totally different 32-bit clocks, 4-channel 10bit ADC, USB POBT, PWM channels and forty six GPIO lines with up to nine outer enter pins these microcontrollers are particularly affordable for mechanical management, restorative frameworks, get to manage and purpose of-offer.

\section{B. LEVEL SENSOR:}

The enhanced series of liquid level sensors incorporates a photo-transistor trigger that provides a digital output that denotes the presence or absence mass. The mode of operation springs from the principle of total internal reflection. Associate led and photo-transistor area unit housed at intervals a plastic dome at the pinnacle of the device. Once no mass is gift, light-weight from the led to internally mirror from the dome to the photo- semiconductor unit. Once liquid covers the dome, the effective ratio at the dome-liquid boundary changes, permitting some light-weight from the led to escape. So the number of light received by the photo-transistor is reduced and also the output switches, indicating the presence of mass.

Features:

- Solid state technology

- Small size

- Digital output

- Pre-wired

- Electrically robust

\section{C. $\quad$ IOT (ESP8266 WIFI) Module:}

The ESP8266 LAN Module could be a self-contained SOC with integrated TCP/IP protocol stack that may provide any microcontroller access to your LAN network. The ESP8266 is capable of either hosting AN application or offloading all Wi-Fi networking functions from another application processor. Every ESP8266 module comes pre-programmed with AN AT command set code, meaning, you'll be able to merely hook this up to your Arduino device and obtain regarding the maximum amount LAN-ability as a WIFI protect offers (and that's simply out of the box)! The ESP8266 module is a particularly price effective board with a large, and ever growing, community.

This module includes a powerful enough on-board process and storage capability that enables it to be integrated with the sensors and alternative application specific devices through its GPIOs with bottom development up-front and bottom loading throughout runtime. Its high degree of on-chip integration permits for bottom external electronic equipment, together with the front-end module, is intended to occupy bottom PCB space. The ESP8266 supports APSD for VoIP applications and Bluetooth co-existence interfaces; it contains a self-calibrated RF permitting it to figure below all operative conditions, and needs no external RF elements. There is almost limitless fountain of knowledge obtainable for the ESP8266, all of that has been provided by superb community support. Within the Documents section below you'll notice several resources to help you in exploitation the ESP8266, even directions on a way to reworking this module into an IOT (Internet of Things) solution!

\section{GSM MODEM:}

This GSM electronic equipment could be an extremely versatile plug and play Quad band GSM electronic equipment for direct and simple integration to RS232. Supports options like Voice, Data/Fax, SMS, GPRS and integrated TCP/IP stack.

Features:

- Quad Band GSM/GPRS 850/900/1800/1900 MHz

- GPRS multi-slot category 10/8

- GPRS Mobile station category B

- Compliant to GSM part 2/2+

- Control via AT commands(GSM 07.07,07.05 and increased AT commands)

- Operation Temperature (-20 deg C to $+55 \operatorname{deg} \mathrm{C})$ 
E. GPS:

The Global Positioning System (GPS) could be a space-based navigation system that gives location and time info altogether atmospheric condition, anyplace on or close to the planet wherever there's an unimpeded line of sight to four or a lot of GPS satellites. The system provides crucial capabilities to military, civil, and industrial users round the world. The United States government created the system, maintains it, and makes it freely accessible to anyone with a GPS receiver.

Features:

- A radical high sensitive and good antenna GPS module.

- Embedded with GPS (Global Positioning System) antenna

- Enables high performance navigation in most tight applications and solid fix even in harsh GPS visibility environments.

\section{F. $\quad$ LCD (LIQUID CRYSTAL DISPLAY):}

LCD stands for liquid crystal display. LCD is finding wide unfold use commutation LEDs (seven phase LEDs or alternative multi-phase LEDs) thanks to the subsequent reasons:

1. The declining costs of LCDs.

2. The flexibility to show numbers, characters and graphics. This is often in distinction to LEDs that are restricted to numbers and a number of characters.

3. Incorporation of a refreshing controller into the digital display, thereby relieving the C.P.U. of the task of refreshing the digital display. In distinction, the led should be reinvigorated by the C.P.U. to stay displaying the information.

4. Simple programming for characters and graphics.

These parts square measure "specialized" for being employed with the microcontrollers, which implies that they cannot be activated by commonplace IC circuits. They're used for writing completely different messages on a miniature LCD.

\section{G. $\quad$ MAX 232:}

The MAX232 is AN IC, initial created in 1987 by Maxim Integrated products, that converts signals from an RS-232 interface to signals appropriate to be used in TTL compatible digital logic circuits. The MAX232 could be a dual driver/receiver and generally converts the RX, TX, CTS and RTS signals.

The drivers offer RS-232 voltage level outputs (approx. $\pm 7.5 \mathrm{~V}$ ) from one + five $\mathrm{V}$ provide via on-chip charge pumps and external capacitors. This makes it helpful for implementing RS-232 in devices that otherwise don't would like any voltages outside the zero $\mathrm{V}$ to + five $\mathrm{V}$ vary, as power provide style doesn't have to be compelled to be created a lot of difficult only for driving the RS-232 during this case. The receivers cut back RS-232 inputs (which could also be as high as \pm twenty five V), to straightforward five V TTL levels. These receivers have a typical threshold of one. $3 \mathrm{~V}$, and a typical hysteresis of zero. $5 \mathrm{~V}$.

\section{ADVANTAGES}

1. Better performance in wireless network

2. Simple system \& reliable Real-time object monitoring.

3. Reduces manpower, cost and time.

\section{APPLICATIONS}

1. Industries

2. Public places

3. Residence

4. Hospitals

5. Schools and colleges etc.

\section{CONCLUSION}

This project work is that the implementation of sensible garbage management system exploitation level sensing element, microcontroller and Wi-Fi module. This technique assures the cleansing of dustbins shortly once the rubbish level reaches its most. If the dustbin isn't cleansed in specific time, then the record is shipped to the upper authority who will take applicable action against the involved contractor. This technique additionally helps to observe the fake reports and therefore will cut back the corruption within the overall management system. This reduces the entire variety of journeys of garbage pickup vehicle and therefore reduces the general expenditure related to the rubbish collection. It ultimately helps to stay cleanliness within the society. Therefore, the sensible garbage management system makes the 
rubbish assortment additional economical. Such systems area unit prone to plundering of elements within the system in numerous ways in which must be worked on.

\section{REFERENCES}

[1] Kasliwal Manasi, H., and B. Suryawanshi Smitkumar. "A Novel Approach to Garbage Management Using Internet of Things for Smart Cities." International Journal of Current Trends in Engineering \& Research (IJCTER) e-ISSN 2455-1392 Volume 2 Issue 5, May 2016 pp. 348 - 353

[2] Zaslavsky, Arkady, and Dimitrios Georgakopoulos. "Internet of things: challenges and state-of-the-art solutions in internet-scale sensor information management and mobile analytics." Mobile Data Management (MDM), 2015 16th IEEE International Conference on. Vol. 2. IEEE, 2015.

[3] Anagnostopoulos, Theodoros, et al. "Top--k Query Based Dynamic Scheduling for IoT-enabled Smart City Waste Collection." Mobile Data Management (MDM), 2015 16th IEEE International Conference on. Vol. 2. IsEEE, 2015.

[4] Hong, Insung, et al. "IoT-based smart garbage system for efficient food waste management." The Scientific World Journal 2014 (2014).

[5] Insung Hong, Sunghoi Park, Beomseok Lee, Jaekeun Lee, Daebeom Jeong, and Sehyun Park, "IoT-Based Smart Garbage System for Efficient Food Waste Management”, the Scientific World Journal Volume 2014 (2014), Article ID 646953.

[6] Vikrant Bhor, Pankaj Morajkar, Maheshwar Gurav, Dishant Pandya4 "Smart Garbage Management System" International Journal of Engineering Research \& Technology (IJERT) ISSN: 2278-0181 IJERTV4IS031175 Vol. 4 Issue 03, March-2015.

[7] P.Suresh1J. Vijay Daniel2, Dr.V.Parthasarathy4” A state of the art review on the Internet of Things (IoT)” International Conference on Science, Engineering and Management Research (ICSEMR 2014) 